\title{
FOTO

\section{Una mirada atenta. El trabajo con la imagen a partir de una aproximación a la obra de Chantal Akerman como performatividad}

\section{An attentive gaze. The work with the image from an approach to the artwork of Chantal Akerman as performativity}

\author{
María Martínez Morales \\ Universidad de Jaén, España \\ mmmorale@ujaen.es \\ https://orcid.org/o0oo-0002-6348-2268
}

\section{Resumen:}

El presente trabajo propone trabajar con la imagen como dispositivo performativo a través una aproximación a la obra de la cineasta Chantal Akerman para recuperar la potencia formadora de la imagen, ante una realidad anestesiada por la repetición de imágenes. Para ello, el texto se organiza según una introducción al trabajo de la cineasta articulado en torno al concepto de performatividad de la imagen como proceso creativo. A continuación, se hace una aproximación a la obra Jeanne Dielman, 23, quai du Commerce, 1080 Bruxelles (1975) como práctica feminista, con ello, se busca contribuir al ejercicio de desplazar la pregunta sobre qué son las imágenes hacia las maneras de hacer de las imágenes. Finalmente, se exponen los resultados de los estudios anteriores como anotaciones para una investigación artística basada en la performatividad como emergencia.

\section{Abstract:}

The present work proposes working with the image as a performative device through an approach to the work of the filmmaker Chantal Akerman to recover the shaping power of the image, in the face of a reality anesthetized by the repetition of images. For this, the text is organized according to an introduction to the work of the filmmaker articulated around the concept of performativity of the image as a creative process. Next, an approach is made to the work Jeanne Dielman, 23, quai du Commerce, 1080 Bruxelles (1975) as a feminist practice, with this, it seeks to contribute to the exercise of shifting the question about what images are towards ways of doing of the images. Finally, the results of the previous studies are presented as annotations for an artistic investigation based on performativity as an emergency.

\section{Palabras clave:}

Chantal Akerman; performatividad; imagen; investigación artística.

\section{Keywords:}

Chantal Akerman; Performativity; Image; Artistic Research. 


\section{Introducción}

¿Cómo abrir los territorios de la imaginación ante un futuro incierto? ¿Cuáles son nuestras metodologías, dispositivos, o formas de sensibilidad a una realidad incontestable? Desde el arte en los años sesenta surgieron prácticas en relación a la imagen como resistencia con la capacidad de abrir nuevas realidades. Tuvo lugar el auge de prácticas, que, según Yayo Aznar, desplegaron poéticas, estrategias y modos de hacer que cuestionaban los géneros y formatos tradicionales, acciones y situaciones que acercaban el arte a la vida (Aznar, 2015). Trabajar con la imagen sigue siendo una necesidad, crear nuevos imaginarios ante una realidad anestesiada por la repetición de imágenes y la importancia que éstas adquieren en nuestras vidas. Situación ya conocida en tiempos anteriores con la invención de la cámara fotográfica, a la que Susan Sontag hace referencia al definir sociedad moderna, cuando una de sus actividades principales es producir y consumir imágenes ejerciendo poderes extraordinarios en la determinación de nuestras vidas, siendo en sí mismas ansiados sustitutos de las experiencias, indispensables en la economía, la estabilidad política y la búsqueda de la felicidad personal (Sontag, 2011).

Así, la importancia del trabajo con la imagen reside en contestar a esa reiteración de imágenes con la creación de otras, la apertura a nuevos imaginarios, formas de vida y mundos posibles. La imagen como formadora de futuros posibles, idea que ya anunciaba Rancière con $\mathrm{El}$ destino de las imágenes, como operaciones que enlazan y desvinculan lo visible y su significación o la palabra y su efecto, que producen y desvían las expectativas (Rancière, 2011). Para ello, se propone la performatividad de la imagen a modo de anotaciones para una investigación artística basada en la obra de la cineasta Chantal Akerman. Desde este enfoque, nos aproximamos al cine de Akerman, como ya defendía Berger en su ensayo Modos de ver, para recuperar la mirada, la importancia que la imagen adquiere en nuestras vidas:

Si el nuevo lenguaje de las imágenes se utilizase de manera distinta, estas adquirirían, mediante su uso un nuevo poder. Podríamos empezar a definir 
con más precisión nuestras experiencias en campos en los que las palabras son inadecuadas. Y no solo experiencias personales, si no también la experiencia histórica esencial de nuestra relación con el pasado; es decir, la experiencia de buscar un significado a nuestras vidas, de intentar comprender una historia de la que podemos convertirnos en agentes activos. (Berger, 2016, p. 33)

Lo que nos interesa aquí no es tanto lo que está presente como su relación con lo ausente y es particular en cada imagen (Berger, 2015). Las nuevas relaciones que ésta pueda crear desde un cine como performatividad que abre a formas próximas a la noción de gesto abordada por Giorgio Agamben:

Si el hacer es un medio con vistas a un fin y la praxis es un fin sin medios, el gesto rompe la falsa alternativa entre fines y medios que paraliza la moral y presenta unos medios que, como tales, se sustraen al ámbito de la medialidad, sin convertirse por ello en fines. (Agamben, 2001, p.4)

Con ello, se busca contribuir al ejercicio de desplazar la pregunta sobre qué son las imágenes hacia las maneras de hacer de las imágenes. Un acercamiento al concepto de performatividad de la imagen desde realidades que no tienen imágenes, que carecen de capacidad para ser imaginadas (Soto, 2020). Abordamos la idea de performatividad como experimentación o sugerencia a la que alude Kaul como narrativa que se expande a través de una secuencia perceptible entre el significado literal y su transformación en sugerencia, y su relación con lo ausente (Kaul, 2021). En este sentido, nos encontramos ante la razón estética Maillard, en un proceso de estar-siendo, en su perpetuo hacerse y deshacerse ante una conciencia implicada en el juego, poiética, creadora o hacedora de realidad. Una razón estética profundamente comprometida en la condición caótica de materia antes de su organización, antes de su visibilidad, de su caída en el tiempo:

En ese hacerse y deshacerse las figuras en la impermanencia de la mirada, el tacto o el oído, la substancialidad de los entes aparece como coincidencia de ritmo y duración: de tiempo. Podría suponerse que esta coincidencia es lo que haría visible un ente para otro; más aún, es lo que le daría carácter de ente, pues lo ente se define por su consistencia, es decir, por el hecho de que consiste en (algo) para mí. (Maillard, 2020, p. 41) 
La performatividad de la imagen para recuperar la ausencia y hacerla presencia, como acto resistencia, así, como Gilles Deleuze propone en su discurso sobre la relación de la obra de arte como resistencia (Deleuze, 1987). Trabajar con la imagen desde procesos creativos para la configuración de mundos posibles requiere explorar nuestras fuerzas imaginantes y liberarlas a través de la práctica como ente activo. Recuperar la capacidad creadora de la imagen a la que alude Maillard, para constituirnos en/con el entorno en un perpetuo suceder (Maillard, 2020). Trabajar con la imagen como medio para dar visibilidad a otros modos de imaginar que puedan ser compartidos como democratización de la experiencia (Sontag, 2011; Hooks, 2017). De esta manera, escogemos la obra de la cineasta Chantal Akerman por el trabajo con la imagen como práctica feminista. Para ello, hacemos una introducción a la obra de la cineasta esbozando las líneas generales que trabaja para aproximarnos a la idea de performatividad de la imagen como construcción identitaria a la que refiere Butler (2002), para movernos al concepto de performatividad como práctica feminista a través de una aproximación a la obra Jeanne Dielman, 23, Quai du Commerce, 1080, Bruxelles (Chantal Akerman, 1975).

Un cine que explora las posibilidades que el medio cinematográfico ofrece, oscilando entre el documental experimental a la instalación audiovisual, de la ficción a la autobiografía. Akerman experimenta con los elementos formales del medio cinematográfico haciendo alusión al cine de vanguardia norteamericano en una banalidad de lo que no aparentemente "nada sucede" como crítica. Con su obra nos sumergimos en un cine feminista que propone indagar en lo cotidiano desde la representación de la mujer que no aparece en el cine tradicional como práctica feminista para generar formas basadas en la imagen como dispositivo performativo.

\section{La imagen en la obra de Akerman}

Nacida en Bruselas, Bélgica, en el año de 1950, Akerman es miembro de una familia judía practicante procedente de Polonia, su vida, en cierta medida, es 
producto del drama de la guerra. Su madre y sus abuelos fueron enviados al campo de concentración en Auschwitz, de donde solo su madre logró escapar con vida. Fue una directora de cine belga, artista y profesora de cine en la European Graduate School. A los quince años descubrió que otra forma de hacer cine era posible, fuera de los márgenes establecidos por la industria norteamericana. En su obra encontramos referentes como Andy Warhol, Jonas Mekas y Michael Snow, Stan Brakhage, Jean-Luc Godard. Con el cine de Jean-Luc Godard, Michel Snow y Andy Warhol comparte la aparente falta de estructura entre la representación del drama y la banalidad de las cosas (Margulies, 1996).

Durante su estancia en Nueva York, al principio de su trayectoria como cineasta, toma contacto con el American Experimental film Scene, y con At Anthology Film Archives a través del cual conoce obras de artistas como Michael Snow, Andy Warhol y de Jonas Mekas, que influyen en su trabajo, especialmente obras como La Région Centrale (1971) de Snow, y los Diary films (1959-1970) de Jonas Mekas. En ellas, encontramos elementos comunes que nos aproximan al trabajo de Akerman en esa relación entre la película y el cuerpo de quien experimenta la obra, como podemos apreciar con la duración extendida, dando lugar a una transformación cinematográfica entre la abstracción y la figuración (Margulies, 1996). Aspectos que nos aproxima al mundo desde la inmediatez de lo que está sucediendo, desde su materialidad, como añade Mangolte en la entrevista cedida a Akerman "en las películas de Akerman estamos quietos y escuchamos el mundo pasar" (Bergstrom, 2001). En su obra podemos destacar, por un lado, la influencia de un cine experimental estructuralista que Akerman acoge proveniente de cineastas de las vanguardias norteamericanas como Michael Snow. Aspectos que apreciamos en la separación entre lo que se representa y la lógica que preside dicha representación. Estos elementos están relacionados, ya que la experiencia personal se presenta a través del modo de enunciación que ha adoptado Akerman, pero no son lo mismo, como si entre la experiencia representada y el espectador se hubiera abierto una separación (Bergstrom, 
2011). La película abre nuevas relaciones entre el cine y el arte próximas a la performance artística que proponen reemplazar la película por su propia enunciación adoptando formas de una película por venir (Bullot, 2021).

Asimismo, encontramos un cine feminista que se articula desde una mirada atenta a lo cotidiano como espacio político que toma la experiencia vivida como materia. Su obra podría ser entendida como un diario, un proceso abierto en constante búsqueda, quizás como una manera de construirse, de comprenderse, de encontrarse, de dar voz a su pasado y al de otras mujeres como podemos ver en obras como To Walk Next to One's Shoelaces, realizada en 2001, donde da voz a su abuela asesinada en Auschwitz leyendo el diario que escribió siendo muy joven. Desde sus primeros trabajos en Saute ma ville en 1968, Je, tu, il, elle en 1974 o Jeanne Dielman, 23, quai du Commerce, 1080 Bruxelles en 1975, hasta sus últimas películas como La Folie Almayer en 2011, pasando por sus instalaciones, diarios y documentales, Akerman cuenta su confinamiento entre el deseo y la locura, el exceso y el orden, como quemadura en la intensidad y crueldad que encuentra en lo cotidiano. Así, aparece la cotidianidad como materialidad, como fisura donde vivir una vida, desde la herida como encuentro (Akerman,2013). Su obra participa del movimiento feminista de los años setenta con películas como Janie's Janie, Three Women (1971) de Geri Ashur o Joyce at 34 (1972) de Joyce Chopra, así como encontramos en Jeanne Dielman, 23, quai du Commerce, 1080 Bruxelles, con una representación alternativa de la mujer en el cine narrativo tradicional.

\subsection{Un estudio de la obra de Akerman para una práctica feminista: Jeanne Dielman, 23, quai du Commerce, 1080 Bruxelles (1975)}

El inicio de la década de los 70 vio la creación de un sólido movimiento de crítica y teoría cinematográfica feminista que influye en un cambio de conceptualización imposible de desligar de la construcción social, cultural y política. Se traduce en una revisión y exploración sobre el discurso, el que se emite y el que se recibe, cuestionando la representación de la mujer en el texto cinematográfico, a su alrededor y como producto del mismo. Los significados generados pierden su aparente neutralidad para hacer visible lo que no era 
hasta el momento (Castro, 2002). Un movimiento feminista que se organizó en torno a la idea de ruptura del flujo de la narrativa, basándose en la necesidad de interrogar y descifrar los procesos de producción fílmica (Coll, 2000; Ladevito, 2014; Molina, 2020). Según Paula Ladevito, nos encontramos, por un lado, con teorías feministas que ponen el énfasis en el espacio cinematográfico como productor de sentidos y significados, y, por otro, con las que han planteado la necesidad de cuestionar los procesos mismos de producción de significados sobre la base de considerarlos ideológicos (Ladevito, 2014).

Desde esta postura, nos aproximamos a la obra Jeanne Dielman, 23, quai du Commerce, 1080 Bruxelles (1975), un cine como dispositivo de denuncia y manifestación de reivindicaciones feministas y femeninas representadas por el cine tradicional, al mismo tiempo que hace una aproximación feminista al quehacer cinematográfico como modo de representación de subjetividad de la cultura patriarcal. Con la obra de Akerman asistimos a un cine que explora nuevas formas, una imagen que cuestiona la constitución ideológica de las convenciones dominantes de representación, que hace visible a una mujer que no había aparecido antes en el cine tradicional. Lo determina la perspectiva feminista en la película es el modo en que se dirige al público, su enunciación, en cómo se representa a la mujer, la imagen que tiene de sí misma y la imagen que otros crean de ella (Bergstrom, 2011). Así, con la obra nos aproximamos a la performance en el sentido que el contexto en sí convierte la acción en performática. Un acto espontáneo corporal que perturba la cotidianidad como performance de resistencia a la censura (Taylor \& Fuentes, 2013). Como Akerman expone en una de sus entrevistas:

Yo creo que se trata de una película feminista porque hago sitio a cosas que nunca o casi nunca, aparecen presentadas de esa forma por ejemplo los gestos diarios de una mujer. Estos ocupan el lugar más bajo dentro de la jerarquía de las imágenes cinematográficas. (Camera Obscura eds. 1977, pp. 115-116)

Jeanne Dielman, 23, quai du Commerce, 1080 Bruxelles (1975) aparece como enunciación de un sujeto, un cuerpo que se hace desde la misma presencia en 
escena, como añade Butler, que no está pasivamente escrito con códigos culturales como si fuera el recipiente sin vida o de un conjunto de relaciones culturales previas. Pero tampoco los yoes corporeizados pre-existen a las convenciones culturales que esencialmente significan a los cuerpos. Presenciamos unos actores que siempre están ya en el escenario, dentro de los términos mismos de la performance (Butler \& Lourties. 1998). Da visibilidad a la opresión de la mujer a través de una forma que será fundamental en su obra: el espacio doméstico como lugar de encierro, pero también de intimidad. De esta manera, se muestra una alineación provocada por el trabajo doméstico y la devastadora sumisión que la protagonista cuenta en Una Familia en Bruselas a través de gestos diarios y la opresión patriarcal marcada en una mirada combativa:

Despojo [las cosas] de todos los añadidos que impiden que las veamos tal y como son. Lo que digo, lo que filmo, en última instancia, tendría que no ser cine, tendría que ser justamente algo que pudiera decirse en la calle, en las cocinas. Resulta que a mí me interesa todo aquello que los demás descartan. La subcultura no es lo contrario de lo bello: aparece cuando se rasca, cuando se purga, cuando se limpia, cuando se quita lo que predomina. Hago películas en las que las personas se ven reflejadas. (Akerman, 2020, p. 9)

En Jeanne Dielman, 23, quai du Commerce, 108o Bruxelles (1975), Akerman se detiene ante lo que pasa cada día, en la representación de los detalles mundanos, cuando Akerman filma la acción cotidiana, con atención cuidadosa a lo que está sucediendo, y, quizás antes no nos detuvimos de la misma manera, a mirar. Es en ese momento, cuando el cuerpo, el espacio y el tiempo adquiere presencia para decir algo, desde la estética de lo performativo como añade Fischer-Lichtela, para el reencantamiento del mundo cuyo centro está en los acontecimientos, una transformación en quienes participan de ella desde la producción performativa de la materialidad y en la emergencia de significados (Fisher, 2011). Así, Akerman presenta una imagen cotidiana, para desde ahí, subvertirla, a través del medio cinematográfico. Construye una representación opuesta al discurso creado en el imaginario del espectador por el cine tradicional, más próximo a prácticas contemporáneas de un 
movimiento feminista que se inició en los sesenta en EEUU con artistas como Martha Rosler, en Semiótica de la cocina (Semiotics of the Kitchen,1975, EEUU, Martha Rosler), donde nos aproximamos a una estética de lo perfomativo para manifestar otros modos de hacer desde en lo cotidiano. Akerman acentúa la rutina doméstica desde una acción cotidiana sin elipsis, respetando el tiempo que ocupa en el espacio cinematográfico, próximo a la obra de Rosler, permitiendo la aparición de una imagen casi siempre omitida en el cine tradicional. La no supresión de los detalles domésticos ofrece un ritmo tedioso, monótono, asfixiante al público, ofrece una imagen alejada de la mujer representada en el cine tradicional (Castro, 2002). La repetición de labores domésticas con la cámara estática comunica la opresión de la protagonista y su distanciamiento emocional de su experiencia de la realidad. Las relaciones sexuales con desconocidos como única fuente de ingresos y las conversaciones sobre sexo con su hijo remiten a una dimensión psicoanalítica que, debido al el violento desenlace, da lugar a un distanciamiento del personaje de su propia psique producido, el que le permitía mantener una existencia soportable (Pérez, 2012).

En Nothing Happens: Chantal Akerman's Hyperrealist Everyday, Margulies analiza los efectos del cine de Akerman, en esa alternancia entre representación y abstracción en su estilo minimalista e hiperrealista. Más concretamente, parece cómo el modernismo y realismo dialógico negocian sus respectivos territorios dentro del cine. Persigue que suceda que "nada suceda" y ofrece una abreviada genealogía de la asociación entre la duración extendida y una temática cotidiana en la Europa de la posguerra (Margulies, 1996). Así, en Jeanne Dielman, 23, quai du Commerce, 1080 Bruxelles, donde Akerman analiza el grado de relación entre la representación y la realidad a través de la atención a "lo sobrante" de la narrativa convencional, característica de la estética del cine realista. La estructura minimalista del cine, mirada hiperrealista redireccionada y energía encontrada en la política de Warhol, una energía que nos traslada hacia el contexto del feminismo político de los setenta (Margulies, 1996; White, 2005). La precisión que caracteriza el trabajo de Akerman necesita ser considerada con cuidado para no acomodarse en el 
típico discurso feminista. De esta manera, nos introducimos en un personaje consciente de la posición patriarcal que vive, mientras con mirada voyeur somos testigo de una violenta y erotizada destrucción reticente del sustituto padre. En ambos, tanto en el cine de ficción como el documental, aparece un hiperrealismo minimalista que lleva a la imagen a amplificar su función denotativa desde una recíproca inestabilidad. En lugar de hacer un giño fílmico dirigido al espectador, Akerman sugiere un cine performativo cómplice a través de los gestos de sus personajes que nos llevan a inscribir, con paradas y flujos en la narración, la posibilidad de alternar lógicas (Margulies, 1996). Nos encontramos ante una estética en el sentido que Margulies describe como aquella que opera en el exceso, en la superposición de registros filmados en la presencia de un cuerpo que acciona para decirlo desde lo performativo.
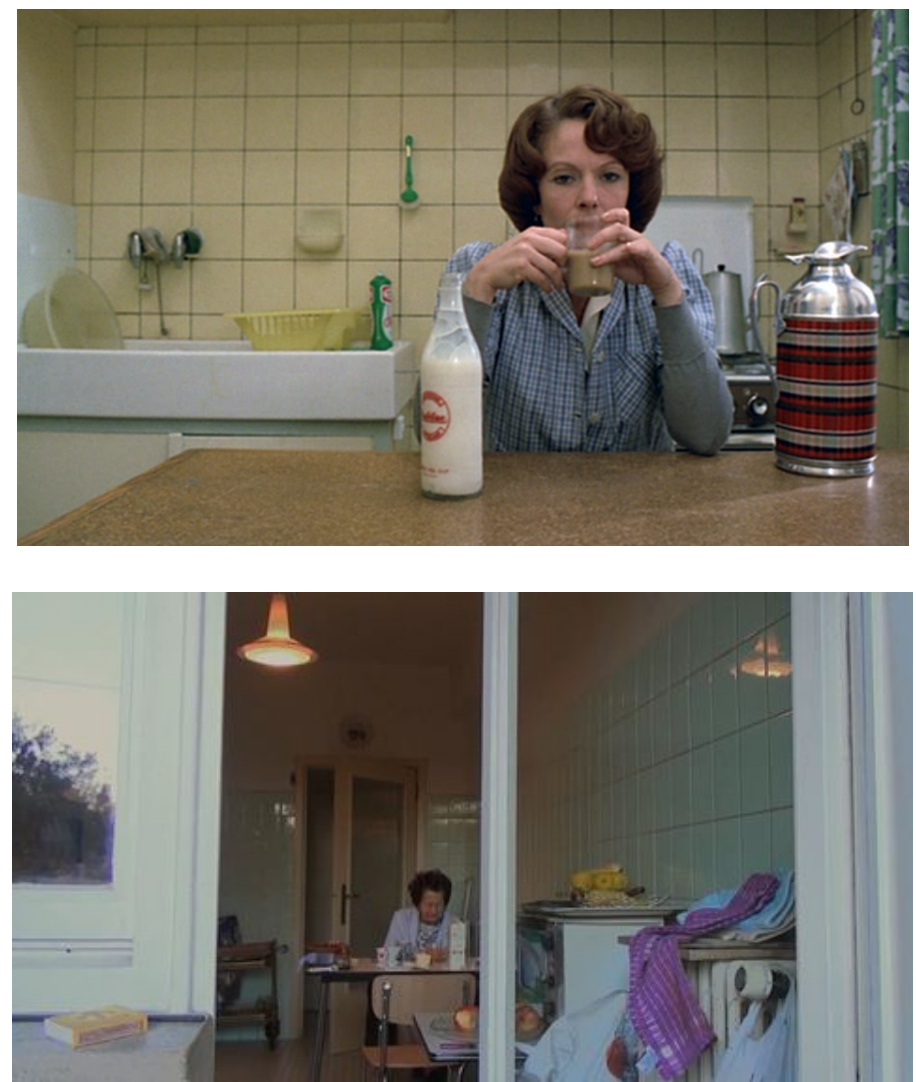

F1. Fotograma de Jeanne Dielman, 23 quai du Commerce, 1080 Bruxelles. Akerman, Bélgica, 1975 .

F2. Fotograma de No Home Movie, Akerman, Bélgica, 2015. 


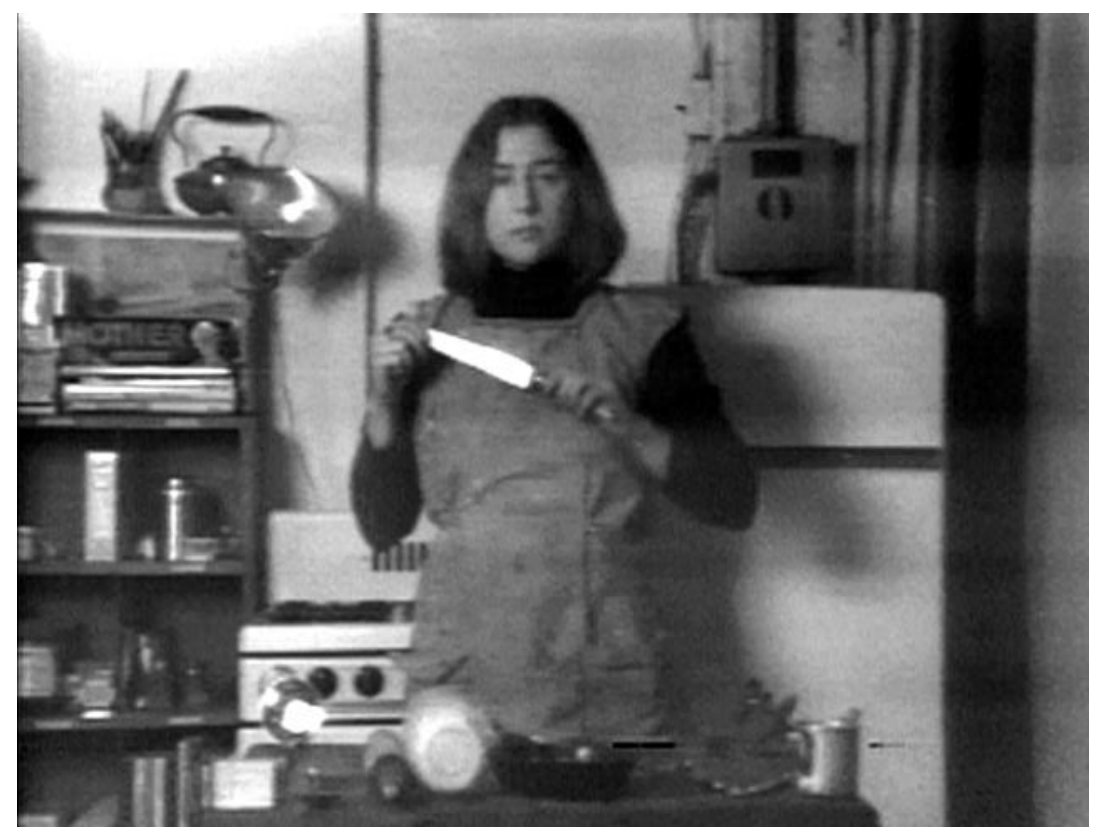

F3. Fotograma de Semiotics of the Kitchen, Marta Roslher, EEUU,1975.

Akerman elige el espacio de lo privado, la intimidad, lo cotidiano, lo que pasa desapercibido pasa a ser filmado para hablar desde el silencio del que aparente no ocurre nada. Su obra pone en valor la cotidianidad de las mujeres, algo que no se había visto nunca, o muy poco, en el cine. Es la cámara espía de una cineasta que da la impresión de captar ese ser interior que aflora cuando no somos vistos, el ser no social e íntimo que nos obliga a observar, una mirada distinta de la mujer, que no la habíamos visto hasta el momento. La imagen muestra el rol de la mujer alienada por el trabajo doméstico producto de una mirada combativa que se ofrece como alternativa a la representación tradicional de la mujer en el cine. Su trabajo aparece como biografía de mujeres que intentan subvertir la situación que por ser mujer estaban abocadas. Parece importante subrayar que es precisamente como pregunta quien habla en el tema de la representación de la mujer, siendo una cuestión crucial en la teoría cinematográfica feminista de la autora. Según Bergstrom:

Akerman comparte con otras directoras un interés especial en analizar cómo se representa a la mujer... su deseo, la imagen que tiene de sí misma, la imagen que otros crean de ella y para ella. Sus películas han propuesto diversas soluciones a la pregunta de "quién habla" cuando se trata de la voz y de la imagen de la mujer. (Bergstrom, 2001, p. 44) 
A través de su cámara nos adentramos en el espacio de la intimidad y lo cotidiano, nos detenemos ante él desde la mirada atenta a lo que hemos visto tantas veces, pero que ahora nos parece extraño. El cine de Akerman evidencia la preocupación con la necesidad de romper con las formas de representación de la mujer. Esta preocupación se apoya en la idea de que en una sociedad sexista, las mujeres no poseen un lenguaje propio y están, por tanto, alienadas con respecto a las formas de expresión culturalmente dominantes. Dicha situación invita a la intervención de la política feminista en los niveles del lenguaje y del significado, este tipo de política puede, por un lado, consistir en un desafío al predominio de ciertas formas de significación, y por otro, un acicate para la creación de formas nuevas, que no respondan a los modelos predominantes (Kuhn, 1991).

Su trabajo transgrede la cotidianidad ajena a través de su auto-representación y traslada el gesto político a su propio cuerpo. Es significativo que los efectos devastadores del Holocausto graviten sobre su obra, una filmografía que se obstina en buscar en el confinamiento, en la dialéctica violenta entre interior y exterior que se deriva de ello y en el rechazo a las convenciones del planocontraplano su posicionamiento político, que no es otro que denunciar la ausencia de la Historia en la construcción del Yo y, por extensión, en el discurso constitutivo del presente (Sánchez \& Fernández, 2016). Según Efrén Cuevas, el cine autobiográfico experimental se caracteriza por una innovación formal en la exposición de la interioridad y la exploración de un nuevo estado de lo visible en el cine, así, la presencia del cineasta al mismo tiempo delante y detrás de la cámara transforma la película subjetiva en un gesto reflexivo, que es también gesto exclusivo, el de un yo que niega o apenas tolera al destinatario (Cuevas, 2010). Por su carácter autobiográfico podemos hacer referencia al cine doméstico, al encontrar las características básicas que le atribuye a este género Janes M. Moran:

Representar lo cotidiano; construir un espacio fronterizo en el que explorar y negociar la propia identidad; en términos personales y comunales, ofrecer una articulación material de la continuidad generacional; construir una imagen de la casa que nos sitúa en el mundo; y ofrecer un formato narrativo para 
comunicar historias familiares y personales, que cubre el ciclo vital a través de acontecimientos rituales. (Moran, 2002, p. 59)

Aquí, la mirada del espectador está dirigida a lo que no se ve en la imagen, lo que no aparece, adquiere importancia la ausencia, la mirada atenta a lo que está sucediendo e nuestro imaginario provocado por la imagen literal de la acción cotidiana. Nos podríamos encontrar ante la imagen poética a la que refiere el fotógrafo Llorenç en ese intento de definir la imagen poética como aquel lenguaje surgido del espacio de la imaginación capaz de crear resonancias que exceden el pensamiento (Llorenç, 2020). Akerman se aproxima al universo cotidiano desde la atención a esa nada de la que nos habla Mekas (2013) con su cine, en lo que pasa inadvertido por su cadencia repetitiva y a la vez mundana. El concepto cine diario aparece de la experimentación de las formas realizadas en torno a las experiencias personales, trabaja en la creación de un espacio centrado en la identidad considerada como construcción compleja. Desde una perfomatividad implicada en el género y en la actuación que depende de estructuras institucionales y de espacios sociales más amplios desde la complejidad de un cuerpo implicado en relaciones qué lo sostienen. De este modo, el cuerpo aparece como un conjunto de relaciones vivas que no puede ser separado del todo de las condiciones infraestructurales y ambientales de su vida y de su actuación (Butler, 2017). Así, la representación de la mujer abre una ventana como mirada íntima para atender a lo que no sucede y lo cambia todo.

\section{Anotaciones para una investigación artística como performatividad}

Desde este enfoque, se ofrece experimentar con la forma y la experiencia, explorar con la imagen y sus posibilidades y así, abrir nuevas formas de relación con el mundo. Para ello, se plantea la investigación artística como performatividad, el trabajo con la imagen desde un proceso de creación artística basada en la obra de Chantal Akerman. 
Una propuesta que inicia en la razón estética que propone Chantal Maillard desde el sentirnos implicadas en un mundo que está en continuo suceder y del que formamos parte (Maillard, 2020). Idea que nos aproxima a la investigación artística como emergencia, desde la sociología de la emergencia de Boaventura de Sousa al entender que la investigación tiene por objetivo mostrar que lo que no existe, en transformar objetos ausentes en objetos presentes (De Sousa Santos, 2010). Para ello, antes de referirnos al concepto de sociología de la emergencia, nos situamos en la sociología de las ausencias que propone De Sousa al señalar que la investigación tiene como objetivo mostrar lo que no existe es activamente producido como no existente, o sea, como una alternativa no creíble a lo que existe (Sousa, 2010). Así, como señala Sousa, su objeto empírico es imposible desde el punto de vista de las ciencias sociales convencionales, por ello, pensar en la investigación artística como performatividad entraña un conocimiento ubicado y tácito, que puede ser mostrado y articulado por medios de experimentación e interpretación (Borgdorff, 2005). La performatividad de la imagen para implicarnos en procesos de creación como investigación para ampliar nuestro conocimiento y comprensión de la realidad, llevando a cabo una investigación en y a través de objetos artísticos y procesos creativos.

De esta manera, con el trabajo se presenta la investigación artística como emergencia, al considerar la sociología de las ausencias desde la formación de imágenes, en ese transformar objetos imposibles en posibles, objetos ausentes en presentes. Según Sousa, nos encontramos ante formas sociales de ausencia o de no existencia producidas por la razón eurocéntrica dominante: lo ignorante, lo residual, lo inferior, lo local o particular y lo improductivo. Así, se propone trabajar con la imagen desde la performatividad para mostrar lo que de alguna forma es producido como no existente como emergencia. Según Sousa, la no existencia es producida siempre que una cierta entidad es descalificada y considerada invisible, no inteligible o desechable" (Sousa, 2010, p. 22). Iniciar procesos creativos con líneas de exploración en torno a la memoria y el recuerdo, imágenes que nos provocan afectos, que nos muevan hacia lugares desprovistos nunca antes visitados. La importancia de la 
memoria reside en trabajar con lo ausente de la imagen para abrir mundos no imaginados:

Toda memoria es individual, no puede reproducirse y muere con cada persona. Lo que se denomina memoria colectiva no es un recuerdo si no una declaración: que esto es importante y que esta es la historia de lo ocurrido, con las imágenes que encierran la historia en nuestra mente. Las ideologías crean archivos probatorios de imágenes, imágenes representativas, las cuales compendian ideas comunes de significación y desencadenan reflexiones y sentimientos predecibles. (Sontag, 2010, p. 76.)

El proceso de creación aparece como práctica experimental para dar forma a la experiencia. Según Roger Odin, recreando los acontecimientos vividos en el marco de una proyección de cine doméstico, los miembros de la familia tienden a incrementar al máximo su placer presente, introduciendo en la diégesis que construyen todo aquello que les hubiera gustado encontrar en lo que vivieron (Odin, 2020). La investigación artística versa sobre lo cotidiano, nos aproximamos a imágenes de un cine doméstico que representen hechos reales, lo resultante bascula finalmente hacia lo imaginario, como recreación mítica del pasado vivido. Una ficción familiar nacida del trabajo de los destinatarios sobre elementos que no poseen por sí mismos ese carácter ficcional.

Expresándonos ya en términos filosóficos, podríamos distinguir dos imaginaciones: una imaginación que alimenta la causa formal y una imaginación que alimenta la causa material o, más brevemente, la imaginación formal y la imaginación material. A la que Gaston Bachelar argumenta en su ensayo Sobre imaginación y materia: El agua y los sueños, donde nos aproxima a la creación poética desde la relación forma y materia, y que nos parecen indispensables estos conceptos. Así, según Bachelar, es necesario que una causa sentimental, íntima, se convierta en una causa formal para que la obra tenga la variedad del verbo, la vida cambiante de la luz. Pero además de las imágenes de la forma, evocadas tan a menudo por los psicólogos de la imaginación, existen imágenes directas de la materia (Bachelar, 1943). La investigación desde lo performativo para abrir procesos creativos como 
propuesta de creación de nuevas imágenes, para imaginar otros cuerpos, todo cuerpo conocido es un cuerpo imaginado o imaginario (Maillard, 2020).

La performatividad para poner el cuerpo a través de la formación de imágenes, en el sentido que propone Marina Garcés, se convierte en la condición imprescindible, primera, para empezar a pensar. Nuestros cuerpos, como cuerpos pensantes y deseantes, imbricados en una red de interdependencias a múltiples escalas. Para cambiar la vida, o para cambiar el mundo, no nos sirven entonces los horizontes emancipatorios y revolucionarios en los términos en los que los hemos heredado. Por eso los cuerpos se desencajan de los discursos y empiezan a hacer lo que sus palabras no saben decir (Garcés, 2016).

\section{Reflexiones}

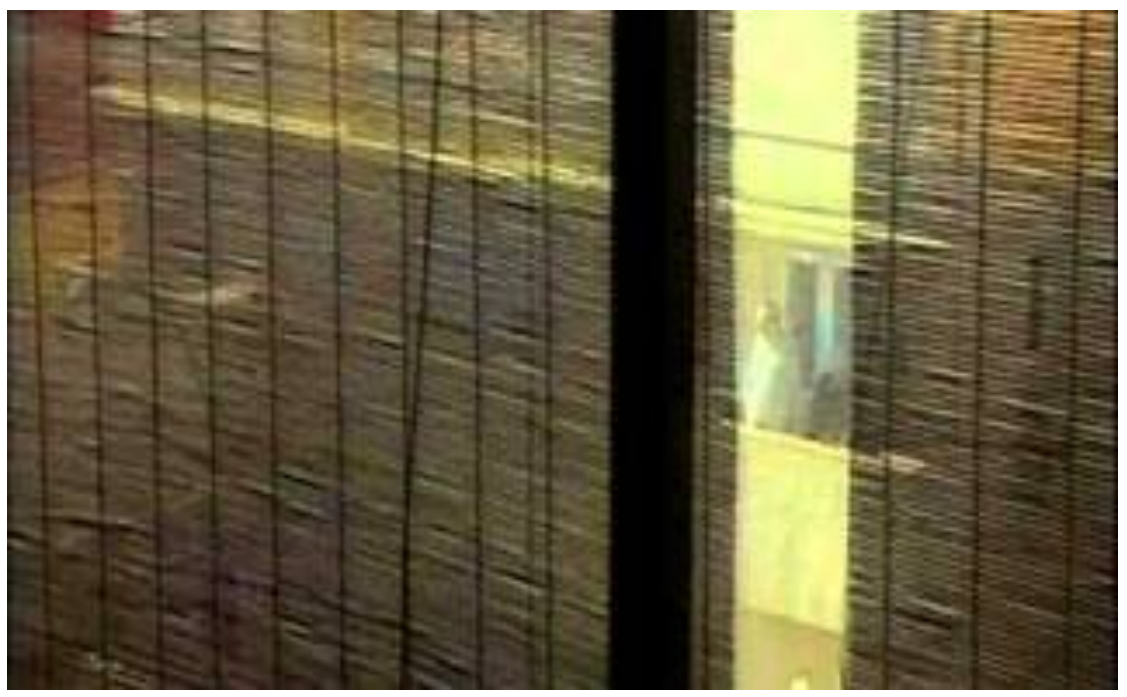

F4. Fotograma de Là-Bas, Akerman, Bélgica, 2006.

Una mirada atenta desde la performatividad nos lleva a considerar las imágenes como como artefactos políticos (Soto, 2020). Nos devuelve la mirada a la habitación propia de Virginia Woolf donde se teje la vida, para sublevar las formas desde lo cotidiano, con el objeto de investigarlo. Trabajar a partir de la mirada atenta para tomar el cuerpo y acercarnos a ese otro modo de hacer derivado del trabajo con la imagen como performatividad, un modo de hacer posible al que alude Diana Toucedo sobre la obra de Chantal Akerman: 
Y veo otra forma de narrar, y veo otra forma de acercarse, y veo otra forma de acariciar, y veo otra forma de amar el mundo, ... veo a una mujer, a lo lejos. Veo a una mujer que se acerca y me susurra al oído que sí, que sí se pueden contar millones de historias que pueden ser ciertas, falsas, verdaderas, reales, ficticias, tramposas, lúcidas, delicadas, bellas y terriblemente atroces. Sí se puede. Y si decimos que hay un montón de cosas que vamos a hacer, la hacemos, y si deseamos crear un montón de cosas, las creamos. Y si las que estamos aquí, frente a este texto, soñamos que podemos tocarnos de otro modo, desnudas, nos tocamos en el mismo sueño o en la realidad. Así lo hiciste. (Toucedo, 2020, p. 73)

Con ello, se propone la investigación artística para la formación de imágenes, que nos abran a la experimentación más que como denuncia, como creadora de nuevas formas. La imagen en Akerman aparece como dispositivo al que refiere Andrea Soto, como discurso de prácticas y saberes que a través de la que cual se organiza la vida, desde ese liberar lo que ha sido capturado, la de ubicarse en la grieta para seguir su potencia, como configuraciones en formación (Soto, 2020, p. 108). Así, la imagen en el trabajo de Akerman no son solo lo visible sino una forma de crear con ella. La performatividad nos instaura a crear un sistema que organiza y estructura para que una existencia pueda ser vista. Por tanto, el trabajo con la imagen en la obra de Akerman nos ofrece caminos para trabajar desde la sociología de las ausencias a la que refiere De Sousa Santos, activando procesos formativos de otras imágenes como acción emancipadora como emergencia al transformar objetos ausentes en presentes. La performatividad de la imagen en Akerman no se limita a caracterizar lo que hacemos, sino que aborda cómo nos afecta el discurso por cuanto establece límites y cambios respecto a lo que hemos dado en llamar nuestra propia acción (Butler, 2017). De ahí, la importancia de trabajar con la imagen encontrando espacio para la transformación, imaginación y la invención desde esa primera fase genética de las imágenes como emergencia. Trabajar desde dentro para desmontar su interior, para liberar un lenguaje nuevo, imaginar posibilidades, crear nuevas formas de organización (Soto, 2020). De esta manera, se propone la investigación artística como emergencia o germen de transformación desde la performatividad de la imagen en la 
medida que activa la formación de imágenes como hacedora de realidad. La imagen como performatividad para implicarnos en un mundo que, según Garcés, significa dejarse afectar para poder entrar en escena, así, implicarse es a la vez una decisión y un descubrimiento: es descubrirse implicado.

Implicarse es retomar «la situación para hacerla tangible» y, por tanto, transformable. Antes que transformar la realidad hay que hacerla transformable. Esto es lo que el poder hoy neutraliza constantemente, cuando nos hace vivir, como si no estuviéramos en el mundo: vidas autorreferentes, privatizadas, preocupadas, anestesiadas, inmunizadas. (Garcés, 2016, p.74)

Con la aproximación a la obra Jeanne Dielman, 23, quai du Commerce, 1080 Bruxelles (1975), asistimos a una imagen que nos mueve como espectadores a que hagamos ese esfuerzo interpretativo y participemos en el proceso de creación de la imagen (Pérez, 2012). El cine de Akerman nos invita a trabajar con la imagen para la implicarnos en un mundo desde la performatividad, imaginar modos de hacer que amplíen los sentidos de experiencia y de posibilidad desde una práctica feminista para una vida más digna de ser vivida.

$\mathrm{Su}$ trabajo abre líneas de investigación en torno a un cine performativo que expone Érik Bullot en Cine de lo posible (2021), un cine que explora el medio para desligarse de él a través de la experimentación de formas próximas a la performance como modo de enunciación. Con Jeanne Dielman, 23, quai du Commerce, 1080 Bruxelles (1975) explora las ausencias, formas de represión oprimidas sobre la mujer, imágenes borradas, confinadas por el relato histórico. Propone una performatividad de la imagen como estrategia política, manera de imaginar mundos posibles o de las posibilidades de mundos que podrían emerger desde lo que no pudo ser (Bullot, 2021). La performatividad describe esta relación de estar implicado en aquello a lo que uno se opone, este modo de volver el poder contra sí mismo para producir modalidades alternativas de poder, para establecer un tipo de oposición política que no es una oposición "pura", una "trascendencia" de las relaciones contemporáneas de poder, sino que constituye la difícil tarea de forjar un futuro empleando recursos inevitablemente impuros (Butler, 2002). 


\section{Referencias bibliográficas}

Akerman, C. (2013). My Mother Laughs. Francia: Mercure de France.

Akerman, C. (2020). Una familia en Bruselas. Madrid: Editorial Tránsito.

Aznar, Y. (2015). Prácticas artísticas contemporáneas. Madrid: Editorial Centro de Estudios Ramón Aceres, S.A.

Bachelar, G. (1978). El agua y los sueños. Ensayo sobre la imaginación de la materia. México: Fondo de cultura económica.

Bergstrom, J. (1997), La femme a la caméra: intrevista di Jane Bergstrom a Babette Mangolte". En Il Cinema di Chantal Akerman, Adriano Apra y Bruno Di Marino (eds.). Roma: Editorial Dino Audino.

Berger, J. (2015). Para entender la fotografía. Barcelona: Editorial Gustavo Gili, S. A.

Berger, J. (2016). Modos de ver. Barcelona: Editorial Gustavo Gili, S. A.

Binimelis, M. (2016). Perspectivas teóricas en torno a la representación de las mujeres en el cine: una breve aproximación histórica / Theoretical Perspectives on Women's Cinema Representations: A Brief Historical Approximation. Secuencias, https://doi.org/10.15366/secuencias2016.42.001

(42).

Borgdorff, H. (2005) El debate sobre la investigación en las artes. Amsterdam School of the Arts: Paises Bajos https://es.scribd.com/document/279835961/BORGDORFF-ElDebate-Sobre-La-Investigacion-en-Las-Artes

Bullot, É. (2021). Cine de lo posible. Madrid: Ediciones Metales Pesados.

Butler, J. \& Lourties, M. (1998). Actos performativos y constitución del género: un ensayo sobre fenomenología y teoría feminista. Debate Feminista, 18.

https://doi.org/https://doi.org/10.22201/cieg.2594066xe.1998.18.52 $\underline{6}$

Butler, J. (2017). Cuerpos aliados y lucha política. Hacia una teoría performativa de la asamblea. Buenos Aires: Paidós.

Butler, J. (2002). Cuerpos que importan. Sobre los límites materiales y discursivos del sexo. Buenos Aires: Paidós.

Butler, J. (1990). El género en disputa: el feminismo y la subversión de la identidad. Buenos Aires: Paidós.

Castro, M. (2002) Feminismo y teoría cinematográfica. Revista del Centro de Ciencias del Lenguaje. 25, 23-48. https://biblat.unam.mx/en/revista/escritos-revista-del-centro-deciencias-del-lenguaje/8 
Camera Obscura eds. (1977), Interview with Chantal Akerman. file:///Users/admin/Downloads/DialnetChantalAkermanYElEspirituDeLosSetenta-2227700\%20(3).pdf

Cuevas, E. (2010). La casa abierta. El cine doméstico y sus reciclajes contemporáneos. Madrid: Ocho y medio.

De Sousa, B. (2010). Descolonizar el saber, reinventar el poder. Uruguay: Trilce.

Deleuze, G. (1987). ¿Qué es el acto de creación? Conferencia dada por Gilles Deleuze en la cátedra de los martes de la fundación FEMIS. https://www.youtube.com/watch?v=dXOzcexu7Ks

Fischer-Lichte, E. (2011). La estética de lo performativo. Madrid: Abada Editorial.

Garcés, M. (2013) Un mundo común. Barcelona: Bellaterra

Giorgio, A. (2001) Notas sobre el gesto. En Medios sin fin. Notas sobre la política, Pre-textos. Valencia: Trafic

González, L.; Raich, Ll. (2020). Sobre la imagen poética. Correspondencia. Cantabria: Muga.

Kaul, M. (2021). Escuchamos y vemos y sentimos y entonces pensamos. Barcelona: Lumière.

Kuhn, A. (1991). Cine de mujeres. Feminismo y cine. Madrid: Ediciones Cátedra, S. A.

Maillard, C. (2021) La razón estética. Barcelona: Galaxia Gutenberg

Margulies, I. (1996). Nothing Happens. Durham. Carolina: Editorial Universidad Duke.

Mekas, J. (2013) En el camino, de cuando en cuando, vislumbré breves momentos de belleza. Comparative Cinema, 2013, No. 3, https://raco.cat/index.php/Comparativecinema/article/view/271786 [View: 31-08-2021].

Molina, B. (2021). El feminismo en la teoría cinematográfica. Un estado de la cuestión. Comunicación y Género, 4(1), 61-71. https://doi.org/10.5209/cgen.71072

Moran, J. (2002) There's No Place Like Home Video. Mineapolis: Editorial Universidad de Minnesota.

Odin, R. (2010). El cine doméstico en la institución familiar. En E. Cuevas Álvarez, La casa abierta. El cine doméstico y sus reciclajes contemporáneos (p. 39-60). Madrid: Ocho y Medio.

Pérez, C. (2012). El cine experimental de mujeres: antecedentes y desarrollo del cine teórico feminista de los 70 en el reino unido. ARBOR Ciencia, Pensamiento y Cultura. Vol. 187 - 758. doi: 10.3989/arbor.2012.758n6010 
Rancière, J. (2011). El destino de las imágenes. Argentina: Prometeo Libros.

Sánchez, S., Fernández, A. A. (2016). La intimidad como acto político. Sobre Grey Gardens y el cine autobiográfico de Chantal Akerman. L'Atalante. Revista de estudios cinematográficos, 22, (77-86).

Sontag, S. (2010). Ante el dolor de los demás. Barcelona: Penguin Random House, Grupo Editorial, S.A.U.

Sontag, S. (2011). Sobre la fotografía. Barcelona: Penguin Random House. Grupo Editorial, S.A.U.

Soto, A. (2020) La performatividad de las imágenes. Madrid: Ediciones Metales Pesados.

Taylor, D. \& Fuentes, M. (2013). Estudios avanzados de performance. México: Fondo de cultura económica.

Toucedo, D. (2020). Solo nos queda el cuerpo. En Akerman, C. (Ed.) Una familia en Bruselas. (pp.74-81) Madrid: Editorial Tránsito.

White, J. (2005). Chantal Akerman's Revisionistic Aesthetic, en Women and Experimental Filmmaking, Jean Petrolle y Virginia Wright Wexman, Urbana \& Chicago, University of Illi-nois Press, 47-68. 